\title{
Lateks bandajı kullanarak ratlarda hareketsizliğin sağlanması*
}

\author{
Tayfun IDE', Berrin SALMANOĞLU², Kemal ALTUNATMAZ \\ 'Gïhane Askeri Tıp Akademisi. Ankara ; ' Ankara Üniversitcsi, Veteriner Fakültesi, Biyokimya Awabaim Dajl, Ankara: \\ ${ }^{3}$ Uludag Universitesi. Veteriner Fakültesi, Cerrahi Bilim Dali.'Biirsi \\ (1)
}

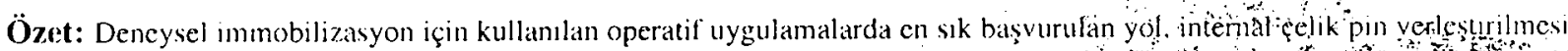

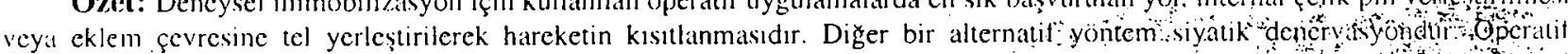

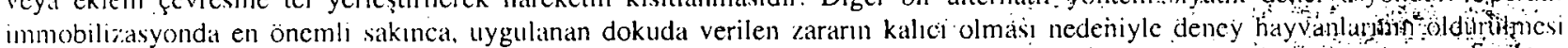

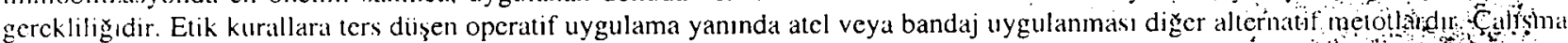

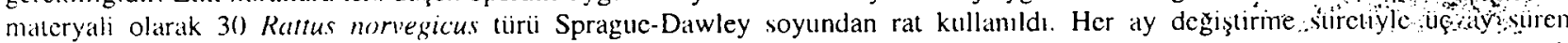

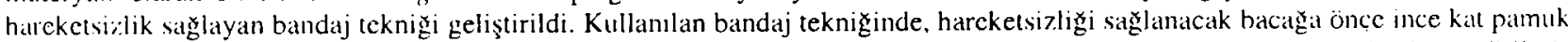
sarıldı. Bınun üzerine ince kat alçılı bandaj uygulandı ve bir süre kuruması beklendi. Sertleșen alçılı bandaj iizeri lateks emdirilmiş pamuk kullamlarak tekrar sarıld. Bir süre kurumas beklenilen lateks sayesinde. en az bir ay süre ile dayamiklı ve deney hayvanma herhangi bir zararı olmayan. klasik yöntemlere alternatif bandaj elde edildi.

Amuhtar kelimeler: Déneysel hareketsizlik, latcks, rat

\section{Maintaining immobilization using latex bandages in rats}

Summary: Most frequently used method for experimental immobilization is to place stecl pin internally or to surround the joint with wire. An alternative way for experimental immobilization is denervation of ischiadic nerve. Major disidvantitge of operative immobilization is permanent tissue damage so the animal must be sacrified. Applying banditge is atlernative way of immobilization to opcration which is not accepted by ethic rules. Thirty Rattus norvegicus species from Sprague-Ditwley breed rats were use ds study materials. By changing the bandage every month a bandage technique was developed which lasted 3 months. In this techmique. firstly a thin cotton layer was wrapped on the leg going to be immobilized. A plastered bandage was applied over the first layer and wated to dry oul. Finally, latex absorbed cotton was over wrapped around the hardened plistered bandige. After drying period of latex, an alternative bandage technique was obtained to classical bandages which can last at leatst one month and can be applied for 3 months

Key words: Experimental immobilization, latex, rat

Ekstremite hareketlerinin kısmen veya tamamen $k_{1}$ sıllandığ 1 araştırmalarda, cklem kıkırdak dokusunda dejenerasjon boyutları izlenmiştir (4). En sık başvurulan metot, operasyon yoluyla eklen içine çelik pin yerleşlirilerek eklemin hareketinin önlenmesidir. Yaygın doku $y: k ı m ı$ nedeniyle dene ğin eklemi tekrar kullanımı muimkün olma\% (6). Eklem harcketsizliğinin siyatik denervasyonla sağlanması kahı felce neden olur (2). Operatif yollardan başka ekstremitelere dışarıdan uygulanan ve kalıcı felç oluşturmayan diğer yöntemler arasında atel uygulanmasi (5) ve ekstremitelere fleksiyon pozisyonunda bandlaj uygulanması (3) saylabilir. Kemik doku melabolizması ve kas doku deģişmlerini izlemek, deneysel eklem hastahkları ve iskclet bozuklukları oluşturmak amacı ile farklı oranlarda hareketsizliğin sağlandığ metotlar belirtilmiştir. Operatif yöntemle eklemé verilen 7arar geri dönüşlü değildir $(7,8)$. Bu çalışmalarda kulJamılan deney hayvanlarının öldürülmesi çoğunlukla kaçınılmazdır.

Bir TÜBITAK projesinin araşırma bölümünü oluşturan bu çalışmada asıl konu, böbrek ve kemik melabolizmalarının, deneysel olarak sağlanan hareketsizlik- ten hangi boyutlarda etkilendiğini bulnaktır. Bu çalışmada amaç, ekștremitelerin hareketinin kısıtlanmasinda, operasyona alternatif olan bandaj uygulanmasina farklı boyut kazandırmaktır. Kullanlacak metot sayesinde, deney hayvanlarında hareket kısıtlanması sağlanırken eklem, kenık, kıkırdak ve yumuşak doku nekrozlarının önlenmesi planlanmışur.

Çalışmanın matcryalini Rattuss norvequicuss türui Sprague Dawley soyundan, outbreed bire bir aile sistemi ile üretilen 7-8 haftalık $350-400 \mathrm{~g}$ ağırlığında random yöntemi ile seçilen 30 erkek rat olışturdu. Ratlar. $21-22^{\circ} \mathrm{C}$ standart sicaklıkta, \%45-55 neme sahip 24 saat 1 şklandırma sistemi ile aydınlatılan odalarda hospilalize edildi. \%24 protein içeren standart rat yemi beslenme için kullanıldı ve içme suyu olarak çeşme suyu verildi. Aşağıda anlatılan yöntem kullanılarak istenilen siire boyunca hareketsizligin kısıtlanması sağlandı. Bacağın tamamun kapsayan ve parmak uçlarında birleşen iki taraflı flasterlerle tutturularak uygulanacak bandajin kaymasi engellendi (Şekil 1). Bunun üzerine ince tabaka bir kat pamuk bacağa sarıldı. Pamukla derinin irrite olmayacağı ortam sağlandıktan sonra ince hazırlanmış alçı bandajı

: Bu ar:ıştırma TÜBITAK tarafindan desteklenmiş̧tir. 


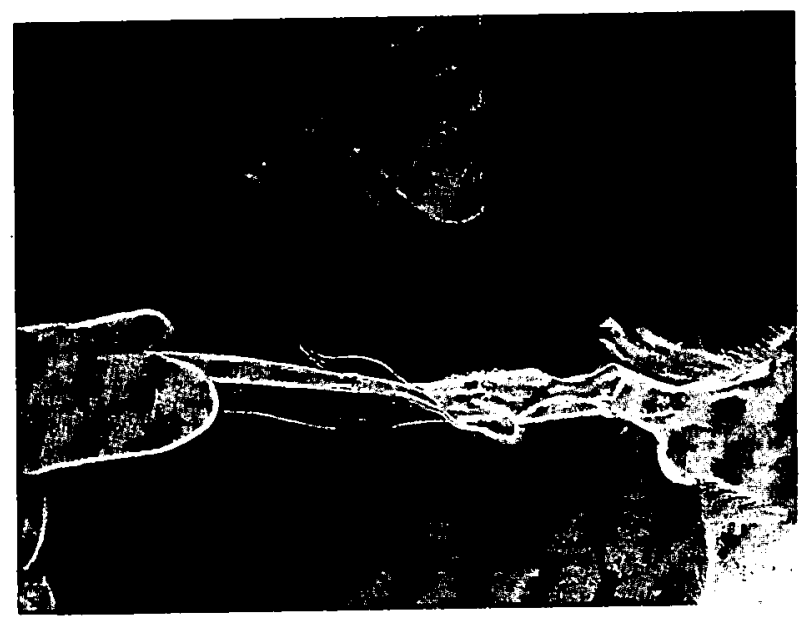

Sekil 1. Kaymayı önleyici flaster uygulanması.

Figure 1. Applying of the surgical tapess to prevent sliding.

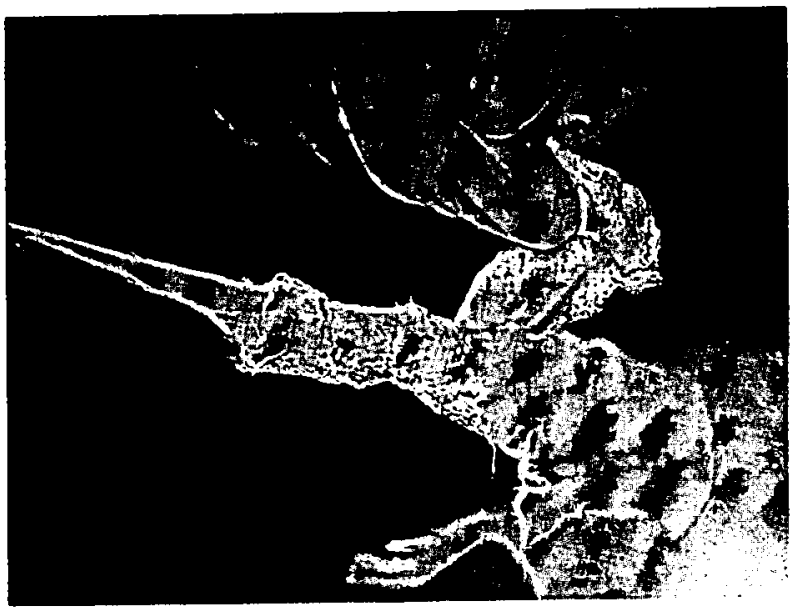

Şekıl 2. Alçılı bandaj uygulanmasıs.

Figure 2. Applying of the plastered bandage.

kullanılarak bacak tekrar sarıldı (Şekil 2). Her iki bacağa aynı işlem yapıldıktan sonra, alçının sertleşmesi beklenildi. Alçı formunu alıp tamamen kuruduktan sonra, rulo şeklindeki lateks (1) cmdirilmiş pamukla (Şekil 3) bacak yeniden sarıldı. Bir süre lateksin sertleşmesi beklendikten sonra bandaj işlemi tamamlandi. Bandaj malzemesini kemirebilme riskine karşı, röntgen filminden hazırlanmıs yakalıklar takıldı. Yakalıkların boyun bölgesinde herhangi bir travma oluşturmaması amacı ile bu bölgeye denk gelen kısımlar pamukla kaplandı (Şekil 4). '

Sonuç olarak, lateks emdirilmiş pamulila elde edilen bandaj kullanılarak uzun süre hareketsizlik sağlanmıştır. Ü̧ aylık süre sonunda beş ayrı ankiloz olayı belirlenmiştir. Elde edilen sonuçlardan yola çıkarak, hareketsizlik çalışacak araştırıcılara bir fikir verecç̆i ve rahat uygulanabileceği yönünden lateks metodu tavsiye edilir.

\section{Kaynaklar}

1. Burt S (1999): What do you need io know about latex. Nursing Mancg, 30, 18-25.

2. Can A (1993): Kullanmamaya bağll osteopenide L-Dopa kullanımın biyomekanik somuçlart. Erciyes Tıp Fak Derg, 2. $4-13$.

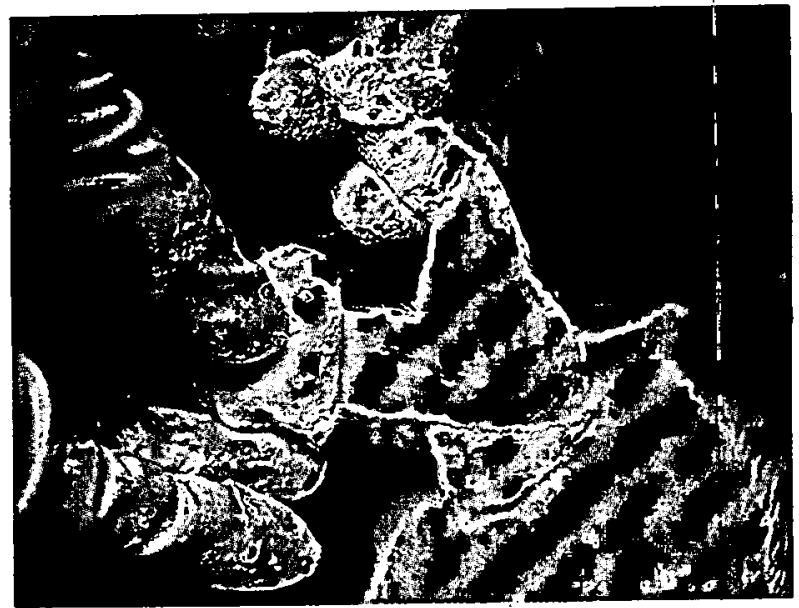

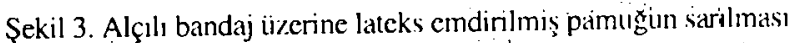
Figure 3. Wrapping of the latex absorbed cotton over the hardened plastered bandiga round.

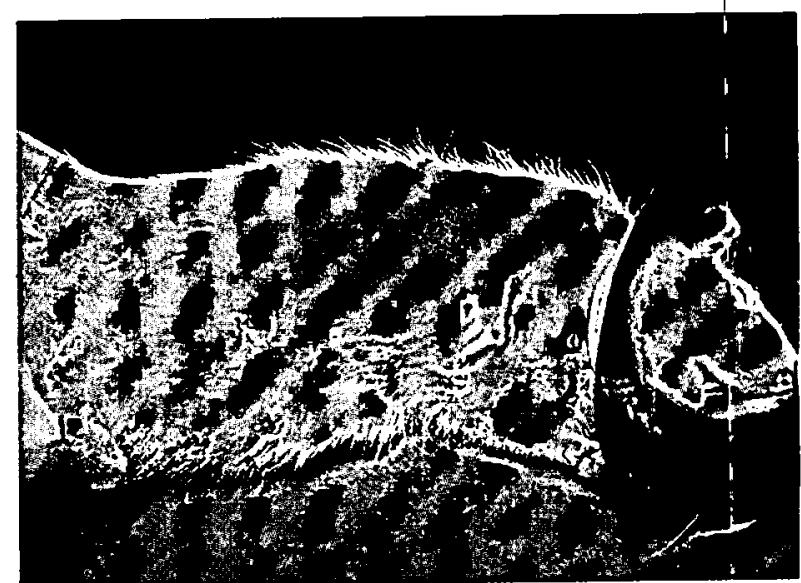

Şekil 4. Röntgen filminden hazırlanan yakalık

Figure 4. The collar made of X-rity films.

3. Evans BE, Eggers GW, Buttler J, Blumel J (1953): $E x$ perimental immobilization of rat knee joints. J Bone Joint Surg, 35, 598-603.

4. Gardner DL (1960): The experimental immobilisation of arthritis. Ann Rheum Dis, 19, 297-299.

5. Haapala J, Arokoski JP, Ronkko S, Agren V, Kosmo JM (2001): Decline after immobilisation and recovery after remobilisation of snowial fluid. Ann Rheum Dis. 60. 55-60.

6. Setton I,A, Mov VC, Muller FJ, Pito JC, Howel DS (1997): Mechanical behaviour and biochemical composition of canine knee cartilage following periods of joint disuse and disuse with remobilisation. Ostcoarth Cirtil. 5. 1-i6

7. Trudel G, Uhthoff HK (20)(0): Contractures seconding to immobility: is the restriction articular or muscular? An experimental longitudinal study in rat knee. Arch Phys Med Rehabil, 81, 6-13.

8. Trudel G, Uhthoff HK, Brown M (1999): Extend and direction of joint motion limitation after prolonged im. mobility: an experimental study in the rat. Arch Phys Med Rehab. 80, 1542-1547.

Gelis tarihi: 11.5.2001/Kabul tarihi : 6.6.2001

Yazışma adresi:

Doç: Dr. Berrin Salmanoğlu

Ankara Üniversitesi, Veteriner Fakültesi,

Biyokimya Anabilim Dali. 06110 Ankara

E-Mail:bsalman@veterinary:ankara.edu.tr 